\title{
Sifat Penyerapan Bunyi Pada Komposit Serat Batang Pisang (SBP) - Polyester
} Khusnul Khotimah ${ }^{1}$, Susilawati ${ }^{2}$, Harry Soeprianto ${ }^{3}$

Program Studi Magister Pendidikan IPA Program Pascasarjana Universitas Mataram ${ }^{123}$ MAN 2 Praya $^{1}$

netchou2010@yahoo.co.id, susilawatihambali@yahoo.co.id, har_soe@yahoo.com

\begin{abstract}
ABSTRAK
Telah dilakukan penelitian mengenai sifat penyerapan bunyi oleh bahan penyerap bunyi berbahan dasar Serat Batang Pisang (SBP) dengan matriks Polyester. Bahan Penyerap Bunyi yang dibuat dengan variasi komposisi fraksi volume yang berbeda, perbandingan fraksi volume SBP dan Polyester yang dibuat yaitu 30\%:70\%, 40\%:60\% dan 50\%:50\%. Metode penelitian dilakukan dalam tiga tahapan yaitu pengambilan serat batang pisang, pembuatan komposit dan pengujian sifat penyerapan bunyi komposit SBP. Pembuatan sampel diawali dengan pengambilan batang pisang, penguraian serat batang pisang, perlakuan alkali dengan $\mathrm{NaOH} 4 \%$, kemudian pencampuran SBP dengan matriksnya polyester. Pencetakan komposit dengan alat cetak tekan dengan penekanan 12 jam. Kemudian dilakukan uji karakterisasi sifat penyerapan bunyi. Uji penyerapan bunyi dilakukan dengan menggunakan signal generator dan sound level meter dengan mengacu pada prinsis metode tabung impedansi melalui pendekatan box akustik. Hasil penelitian komposit SBP Polyester mampu menyerap bunyi dengan koefisien serapan bunyi $\alpha=0,84$ pada fraksi volume serat 50\%, hal ini menunjukkan bahwa komposit SBP mampu menyerap bunyi dengan baik untuk frekuensi rendah dan frekuensi sedang, sesuai dengan standar ISO 11654:1997 (E) dimana koefisien serapan bunyi bahan akustik minimal sebesar $\alpha=0,15$.
\end{abstract}

Kata Kunci: Komposit, Serat Batang Pisang, Bahan Penyerap Bunyi, Polyester.

\begin{abstract}
This research conducted to find the physical properties of the absorption of sound from banana stem fiber (Serat Batang Pisang/SBP) with polyesters' matrix. The sound absorbent material made with a variety of different volume fraction composition. The comparison between the SBP and the volume fraction of the polyester is made of 30\%: 70\%, 40\%: 60\% and 50\%: 50\%. The method of research was done in three stages: making banana stem fiber, manufacturing composite and testing of composite SBP. Composite testing includes physical properties (sound absorption). Preparation of the samples started by taking a banana stem, decomposition banana stem fiber, alkali treatment with $\mathrm{NaOH} 4 \%$, then mixing the SBP with the matrix polyester. Manufactured the composites by press the materials on the molding for 12 hours, then tested to find physical properties. Sound absorption test performed using a signal generator and a sound level meter with the principle of the impedance tube method through acoustic box approach as a reference. The results of the study showed that SBP with polyester composite capable to absorb the sound with sound absorption coefficient $\alpha=0.84$ at $50 \%$ fiber volume fraction. Thus SBP composites can absorb sound for low and medium frequency, based on the standard ISO 11654:1997 (E) where the minimum of sound absorption coefficient of acoustic materials is $\alpha=0.15$.
\end{abstract}


Keywords: Composite, banana stem fiber, sound absorber materials, polyester.

\section{Pendahuluan}

Teknologi peralatan semakin berkembang dan meningkat, kebutuhan manusia baik primer atau sekunder juga semakin meningkat. Baik peralatan yang berupa sarana informasi komunikasi produksi teknologi dan hiburan. Seiring dengan penggunaan peralatan-perlatan tersebut, permasalahan lingkunganpun muncul seperti halnya polusi suara /kebisingan. Seperti yang terjadi di sekolah-sekolah yang berlokasi di pinggir jalan besar dengan arus kendaraan lumayan ramai sehingga menyebabkan proses pembelajaran terganggu. Selain itu, kebisingan sangat erat hubunganya dengan kesehatan seseorang, yaitu dapat menyebabkan gangguan kesehatan seperti tekanan darah tinggi.

Peraturan menteri Kesehatan No. 718 Tahun 1987 tentang kebisingan yang berhubungan dengan kesehatan menyatakan pembagian wilayah dengan empat zona. Untuk zona $\mathrm{C}$ yang antara lain perkantoran, perdagangan dan pasar dengan kebisingan sekitar 50 - $60 \mathrm{~dB}$. Pada zona ini khususnya banyak disebabkan oleh bunyi knalpot kendaraan bermotor. Karena itu perlu adanya upaya untuk mengurangi dampak negatif tersebut. Pengurangan kebisingan dengan biaya murah dan teknologi yang sederhana, memerlukan perencanaan yang matang. (Nurdiana \& Isranuri, 2011)

Salah satu upaya untuk mengurangi polusi suara/tingkat kebisingan didalam gedung, sekolah-sekolah dapat dilakukan dengan menggunakan bahan peredam suara atau material akustik, yaitu material yang bersifat menyerap atau meredam bunyi sehingga kebisingan dapat berkurang (Nurdiana \& Isranuri, 2011). Bahan peredam suara atau bahan akustik adalah bahan khusus yang dibuat untuk fungsi menyerap bunyi pada frekuensi tertentu. Material yang bersifat lembut, berpori dan berserat diyakini mampu menyerap energi suara yang mengenainya. Dari ketiga bahan tersebut, dewasa ini sedang dikembangkan bahan berserat seperti serat batang pisang.

Batang pisang merupakan bahan berpori yang dapat digunakan sebagai peredam suara, batang pisang merupakan limbah pertanian yang belum banyak dimanfaatkan. Sekarang ini serat batang pisang mulai diperhatikan oleh peneliti sebagai serat pakaian dan juga kertas, namun pemanfaatannya belum optimal. Selain itu juga banyak dimanfaatkan sebagai pintalan benang untuk kain rajut, interior mobil, furniture, dan kontruski ringan. 
Hal ini berarti, jika limbah batang pisang bisa termanfaatkan dengan baik, maka masalah limbah menjadi berkurang. Menurut Nuranni (2012) batang pisang memiliki berat jenis $0,29 \mathrm{gram} / \mathrm{cm}^{3}$ dengan ukuran panjang serat 4,2 -5,46 mm dan kandungan lignin 33,51\%.

Pelepah pisang juga memiliki jaringan selular dengan pori-pori yang saling berhubungan, serta apabila telah dikeringkan akan menjadi padat menjadikannya suatu bahan yang memiliki daya serap yang cukup bagus. Menurut Didit (2012), Maharani dalam penelitiannya membuat bahan peredam suara dari serat batang pisang kepok dan mampu meredam bunyi lebih tinggi dari pada pisang raja, pisang susu dan pisang batu yaitu sebesar $63 \%$ untuk frekuensi $200 \mathrm{~Hz}$, kemampuan serat batang pisang kepok dalam meredam bunyi pada ferkuensi rendah 125 hertz hingga 51 persen, tetapi pada frekuensi 160 hertz tidak sampai meredam 21 persen. Sedangkan pada frekuensi tinggi 2.000 hertz, bisa meredam sampai 55 persen, dan pada frekuensi 1.600 hertz hanya 40 persen.

Resin poliester tak jenuh atau sering disebut poliester merupakan matrik dari komposit. Resin ini termasuk juga dalam resin termoset. Pada polimer termoset resin cair diubah menjadi padatan yang keras dan getas yang terbentuk oleh ikatan silang kimiawi yang membentuk rantai polimer yang kuat. Resin termoset tidak mencair karena pemanasan. Pada saat pencetakan, resin ini tidak perlu diberikan tekanan, karena ketika masih cair memiliki viskositas yang relatif rendah, mengeras dalam suhu kamar dengan penggunaan katalis tanpa menghasilkan gas (tidak seperti resin termoset lainnya). Pada umumnya resin poliester kuat terhadap asam kecuali asam pengoksida, tetapi memiliki ketahanan yang rendah terhadap basa. Jika resin ini dimasukkan ke dalam air mendidih selama 300 jam maka akan pecah dan retak-retak. Secara luas poliester digunakan dalam bentuk bahan komposit.(Noni, 2013)

Poliester merupakan jenis material polimer thermosetting, yaitu jenis material dimana terbentuknya ikatan dibantu oleh panas, katalis atau gabungannya. Matriks ini dapat menghasilkan keserasian matriks-penguat dengan mengontrol faktor jenis dan jumlah komponen, katalis, waktu, dan suhu. Sifatnya tahan creep, memadai selaku perekat struktur berbeban berat, serta tahan kondisi ekstrim panas, radiasi, kelembaban, dan tahan kimia.(Nasmi, 2011).

Berdasarkan latar belakang tersebut, maka dalam penelitian ini, disintesis material komposit SBP Poliester dengan fraksi volume serat batang pisang (SBP) terhadap sifat 
penyerapan bunyi dan diharapkan material komposit SBP Poliester mampu menyerap bunyi dengan baik.

\section{Tinjauan Pustaka}

Material komposit adalah material yang terbuat dari dua bahan atau lebih yang tetap terpisah dan berbeda dalam level makroskopik selagi membentuk komponen tunggal. Bahan komposit (atau komposit) adalah suatu jenis bahan baru hasil rekayasa yang terdiri dari dua atau lebih bahan dimana sifat masing-masing bahan berbeda satu sama lainnya baik itu sifat kimia maupun fisikanya dan tetap terpisah dalam hasil akhir bahan tersebut (bahan komposit). Karena karakteristik pembentuknya berbeda-beda maka akan diperoleh suatu material baru yang lebih baik dari material pembentuknya. Material pembentuk komposit ada 2 yaitu penguat (reinforcement) dan pengikat (matriks). Sifat komposit bahan sangat dipengaruhi oleh sifat dan distribusi unsur penyusunnya, serta interaksi antara keduanya. Parameter yang lain yaitu bentuk, ukuran orientasi dan distribusi dari penguat dan sifat-sifat matriksnya. (Kartini, dkk. 2002).

Adanya dua penyusun komposit atau lebih menimbulkan beberapa daerah dan istilah penyebutannya: matriks(penyusun dengan fraksi volume terbesar), penguat (penahan beban utama), interphase (pelekat antar dua penyusun) dan interface (permukaan phase yang berbatasan dengan phase lain).

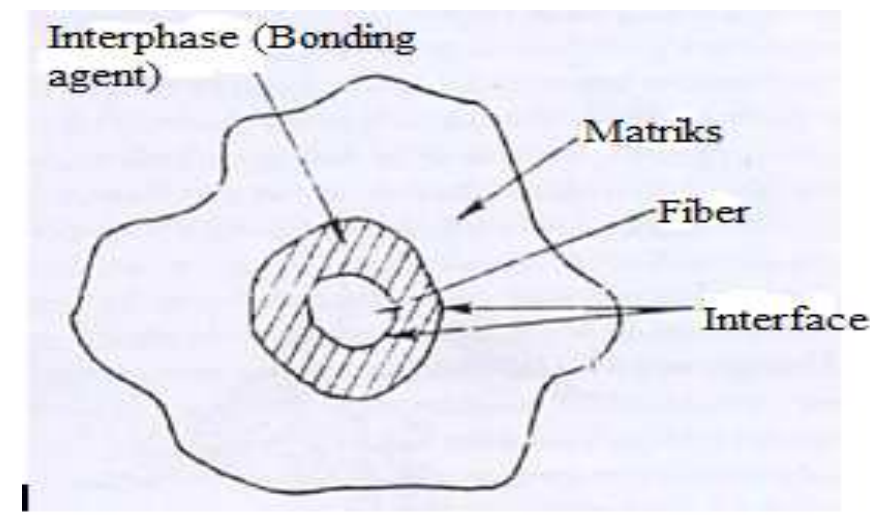

Gambar 1. Bagian-bagian komposit (Mitchel, 2010)

Material akustik adalah material yang fungsinya adalah untuk menyerap suara. Material akustik adalah suatu bahan yang dapat menyerap energy suara dating dari sumber suara. Pada dasarnya semua bahan dapat menyerap energy suara, namun besarnya energy yang diserap berbeda-beda untuk tiap bahan. Energi suara tersebut dikonversi menjadi energy panas, yang merupakan gasil dari pergeseran (friksi) dan kekuatan (resistansi) dari 
berbagai material untuk bergerak dan berdeformasi. Sama halnya dengan besar energi suara yang sangat kecil bila dilihat dalam satuan Watt, energi panas yang dihasilkan juga sangat kecil sehingga secara makrokopis tidak akan terlalu terasa perubahan temperature pada bahan tersebut.

Energi suara datang yang tiba pada suatu bahan akan diubah sebagian oleh bahan tersebut menjadi energi lain, seperti misalnya getar (vibrasi) atau energi panas. Oleh karena itu, bahan yang mampu menyerap suara pada umumnya mempunyai struktur berpori atau berserat. Nilai absorpsivitas suara dihitung menggunakan persamaan dibawah ini:

$$
\alpha=\frac{W_{a}}{W_{i}}
$$

Dimana Wa dan Wi masing-masing adalah daya suara yang diserap dan daya suara yang tiba pada permukaan bahan.

Penyerapan bunyi adalah perubahan energi bunyi menjadi suatu bentuk lain, biasanya panas ketika melewati suatu bahan atau ketika menumbuk suatu permukaan (Doelle, 2006). Efisiensi penyerap bunyi suatu bahan pada suatu frekuensi tertentu dinyatakan oleh koefisien penyerap bunyi. Koefisien penyerapan bunyi suatu permukaan adalah bagian energi bunyi datang yang diserap atau tidak dipantulkan oleh permukaan. Koefisien ini dinyatakan dalam huruf Greek $\alpha$. Nilai $\alpha$ dinyatakan dalam bilangan antara 0 dan 1. (Doelle,2006).

Penyerap bunyi sering disebut papan akustik, ditawarkan dalam banyak tipe baik yang digunakan untuk menyerap frekuensi tinggi, menengah, maupun rendah. Pemakaian bahan penyerap harus didasari pada pemahaman akan fungsi akustik ruang, yaitu sebagai berikut:

1. merubah gelombang bunyi menjadi kalor, ditunjukkan dengan adanya pori-pori

2. merubah gelombang bunyi menjadi mekanis (resonansi), ditunjukkan dengan bahan yang lembek dan mudah bergetar (Satwiko, 2009)

Konsep dari penyerapan Bunyi (Acoustic Absorption) merujuk kepada kehilangan energi yang terjadi ketika sebuah gelombang bunyi menabrak dan dipantulkan dari suatu permukaan benda. Penyerap jenis berserat adalah penyerap yang paling banyak dijumpai, sebagai contoh jenis selimut mineral wool (rockwool atau glasswool). Penyerap jenis ini 
mampu menyerap bunyi dalam jangkauan frekuensi yang lebar dan lebih disukai karena tidak mudah terbakar. Namun kelemahanya terletak pada model permukaan yang berserat sehingga harus digunakan dengan hati-hati agar lapisan serat tidak rusak/cacat dan kemungkinan terlepasnya serat-serat halus ke udara karena usia pemakaian.

Pada umumnya bahan yang berpori (porous material) akan menyerap energi suara yang lebih besar dibandingkan dengan jenis bahan lainnya, karena dengan adanya poripori tersebut maka gelombang suara dapat masuk kedalam material tersebut. Energi suara yang diserap oleh bahan akan dikonversikan menjadi bentuk energi lainnya, pada umumnya diubah menjadi energi kalor. Penyerap dari bahan berserat dipasarkan dari berbagai ketebalan dan kerapatan sehingga yang paling sesuai dengan frekuensi bunyi yang hendak diserap.

Serat batang pisang yang termasuk dalam jenis vascular fibers, berasal dari batang tanaman pisang (Musa x Paridasiaca). Selain mudah diperoleh, serat pisang juga memiliki potensi untuk digunakan bahkan di dalam dunia industri sekalipun. Salah satu family dari tanaman pisang yaitu abaca telah lama digunakan dalam pembuatan uang, kantung teh, dan kertas manila yang terkenal. Bahkan, kekuatan tariknyapun termasuk salah satu yang tertinggi di antara serat-serat alam lainnya. Serat batang pisang diperoleh dari batang palsu (pseduo-stem) pokok pisang merupakan serat yang mempunyai sifat mekanik yang baik.

Identitas morfologi dari penampang batang pisang terhadap serat batang pisang menunjukkan bahwa serat batang pisang memiliki banyak rongga dengan struktur permukaannya lebih menyerupai busa (sponge). Dari penampang melintangnya serat-serat tersebut mempunyai dinding dan lubang tengahnya yang disebut humen. Senyawa yang melekat satu serat dengan serat lainnya disebut lignin, yang terdapat di dalam lamela tengah. Lignin yaitu bagian yang terdapat dalam lamella tengah dan dinding sel yang berfungsi sebagai perekat antar sel, merupakan senyawa aromatic berbentuk amorf. Komposit akan mempunyai sifat atau kekuatan yang baik apabila mengandung sedikit lignin, karena lignin bersifat kaku dan rapuh.

Resin poliester merupakan resin yang paling banyak digunakan dalam berbagai aplikasi yang menggunakan resin termoset, baik secara terpisah maupun dalam bentuk material komposit. Resin Poliester seperti yang telah dijelaskan diatas memiliki banyak kelebihan sekaligus beberapa kelemahan, dalam aplikasi komposit resin poliester dalam hal ini poliester tidak jenuh, biasanya ditambahkan penguat (reinforced) berupa serat. Serat 
yang digunakan sebagai penguat adalah bisa berupa serat gelas, serat alam, serta carbon dan berbagai serat lainnya. Karena sifatnya yang polar, hampir semua jenis serat bisa dikombinasikan dengan resin poliester.

Penambahan filler/ fiber pada resin poliester dilakukan dengan berbagai macam alasan, namun secara umum penambahan fiber pada material komposit dengan matriks resin poliester bertujuan untuk:

- Mengurangi biaya dari proses moulding/ pencetakan

- Untuk memfasilitasi proses moulding/ pencetakan

- Untuk memberikan sifat-sifat mekanik tertentu pada material yang ingin dibuat.

Dalam melakukan fabrikasi menggunakan resin poliester, kita harus menyakinkan bahwa resin dan additif lainnya harus sudah tersebar secara merata sebelum katalis ditambahkan. Dan dalam proses pengadukan jangan sampai ada udara yang terperangkap didalamn larutan komposit. Karena udara itu kemudian akan menyebabkan sifat mekanik dari material komposit berkurang secara signifikan. Kemudian pemberian katalis juga harus diperhatikan, terlalu banyak katalis akan mengakibatkan proses pengerasan terlalu cepat sedangkan jika terlalu sedikit komposit yang terbentuk akan terbentuk under-cure.

\section{Metodologi}

Alat yang digunakan untuk karakteristik sampel pada penelitian ini adalah box akustik $80 \mathrm{~cm}$ x $20 \mathrm{~cm}$ x $26 \mathrm{~cm}$, signal generator merek Gwinstek $5 \mathrm{MHz}$, Loud speaker 8 ohm, 1,5 Watt dan Desibel meter merek Lutron, dengan spesifikasi batas maksimum hingga $130 \mathrm{~dB}$ dan ketidakpastian $0,1 \mathrm{~dB}$.

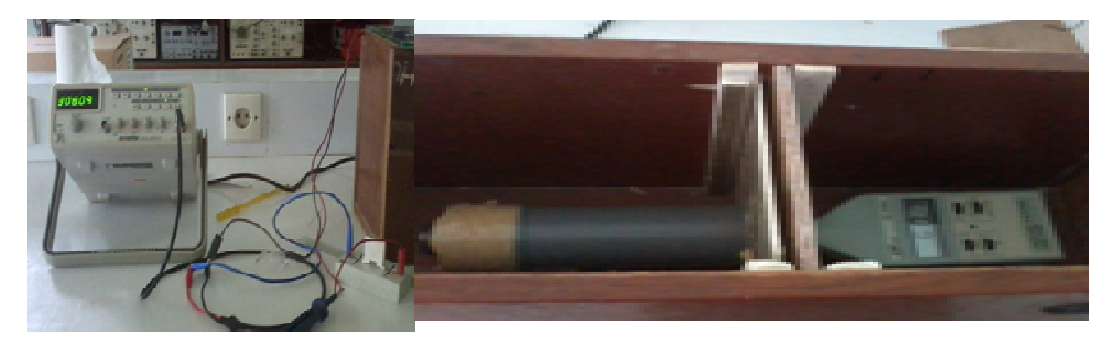

Gambar 2. Seperangkat alat uji penyerapan bunyi 
Sedangkan bahan yang digunakan adalah serat batang pisang digunakan sebagai penguat komposit, polyester dan katalis MEKPO (Metil Etil Keton Peroxide) digunakan sebagai matriks atau pengikat komposit.

Penelitian ini menggunakan metode hand lay up. setelah itu pengambilan serat dilakukan dengan memilih batang pisang yang sudah layu, kecoklatan. Kemudian direndam hingga busuk, dilanjutkan dengan penguraian serat dan pencucian hingga bersih. Perlakuan alkali dilakukan dengan perendaman serat dalam $\mathrm{NaOH} 4 \%$ selama 2 jam. setelah SBP kering, dengan dicampur dengan matriks polyester kemudian diaduk hingga merata dan dicetak. Sampel uji abasorpsi berukuran 241 x 161 x $7 \mathrm{~mm}$

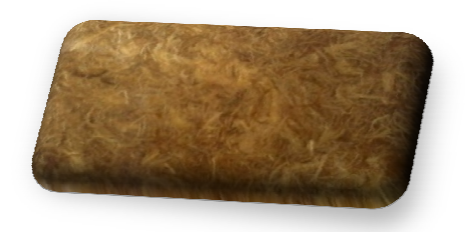

Gambar 3. Sampel uji absorpsi bunyi

\section{Hasil dan Pembahasan}

Hasil pengujian penyerapan bunyi diperoleh dari perbandingan intensitas sebelum dan setelah melewati sampel. Pengujian yang dilakukan menghasilkan data seperti pada gambar 3 berikut. Perambatan gelombang yang melalui bidang pembatas akan mengalami pemantulan, penyerapan dan transmisi. Itu berarti sebagian energy bunyi ada yang dipantulkan, sebagian diserap dan sebagian lagi diteruskan ke balik bidang batas. Proporsi energy bunyi yang diserap, dipantulkan atau diteruskan ditentukan oleh koefisien serap $(\alpha)$. Koefisien serap (absorpsi) adalah angka tanpa satuan yang menunjukkan perbandingan antar energy bunyi yang tidak dipantulkan (diserap) oleh material pembatas berbanding keseluruhan energy bunyi yang mengenai material pembatas.

Besar kecilnya nilai koefisien serap selain bergantung pada frekuesni bunyi dan karakteristik material pembatas juga bergantung pada sudut jatuh gelombang bunyi. Meski pada prakteknya factor sudut tidak memberikan pengaruh yang penting karena saat gelombang bunyi merambat ke segala arah, sudut dating yang mengenai permukaan bidang batas dapat berbeda-beda besarnya (Mediastika, 2009).

Terkait dengan kemampuan serap material ada 3 faktor yang perlu diperhatikan yaitu ketebalan, rongga udara dan kerapatan. Seringkali muncul pendapat bahwa material yang lebih tebal akan memberikan kemampuan serap yang lebih baik. Hal ini benar hanya 
untuk bunyi bverfrekuensi rendah namun tidak selalu untuk frekuesni tinggi. Kemampuan serap terhadap bunyi frekuensi rendah juga dapat ditingkatkan dengan menempatkan penyerap pada jarak tertentu dari kontruksi ruang sehingga tercipta rongga udara. Sementara itu dari aspek kerapatan material, untuk menjadi penyerap yang baik, material dituntut untuk memiliki kerapatan sedang. Pada tingkat kerapatan rendah atau terlalu renggang, penyerapan tidak dapat terjadi. Demikian pula untuk kerapatan yang tinggi, permukaan material penyerap cenderung berubah menjadi memantulkan. (Mediastika, 2009)
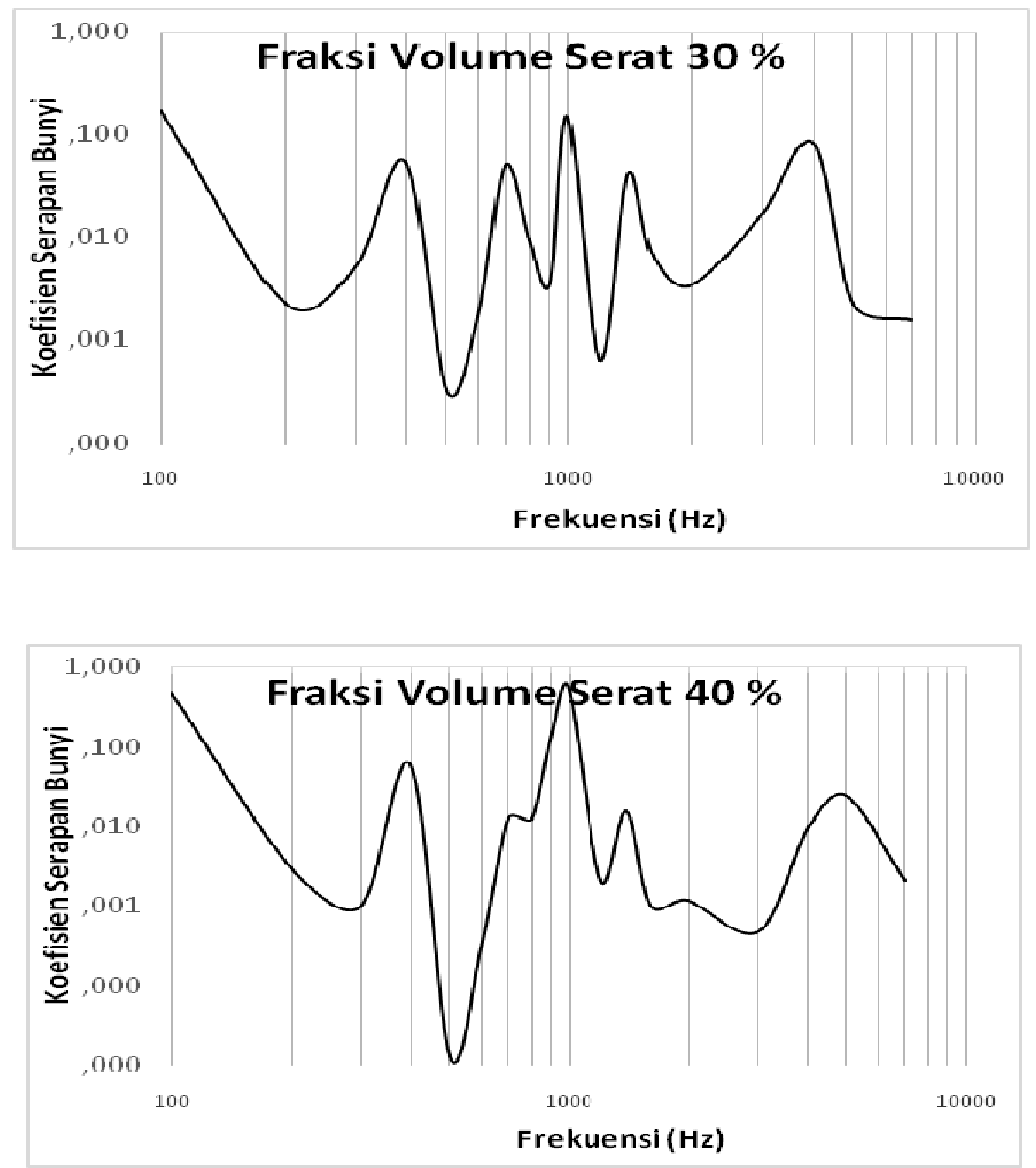


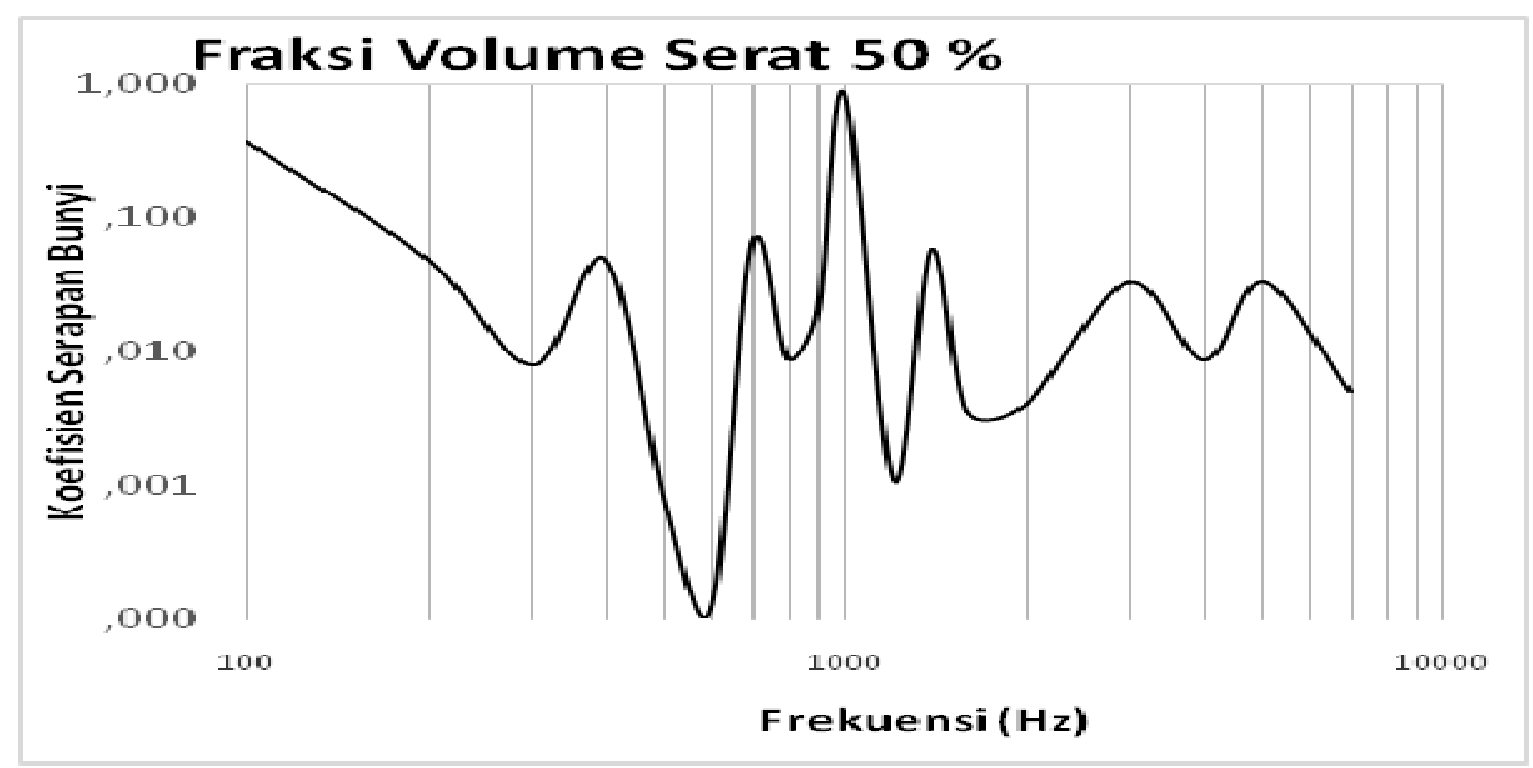

Gambar 4.Grafik hubungan frekuensi dengan Koefisien Serpan Bunyi

Dari gambar 4 diperoleh data penyerapan bunyi dengan menggunakan komposit SBP Polyester dengan ketebalan $8 \mathrm{~mm}$ dan fraksi volume SBP 30\%, $40 \%$ dan 50\%, dengan koefisien serapan bunyi tertinggi pada frekuensi sedang $(1000 \mathrm{~Hz})$ sebesar $\alpha=$ 0,84. Sedangkan pada frekuensi $100 \mathrm{~Hz}$, koefisien serapan tertinggi mencapai $\alpha=0,48$, dengan fraksi volume SBP $40 \%$. Penambahan serat batang pisang ataupun matriks mempengaruhi besar kecilnya penyerapan bunyi, semakin keras suatu material dengan kerapatan tinggi maka material cenderung memantulkan bunyi.

Sehingga pada fraksi volume $50 \%$, dengan kerapatan $\rho=1,03 \mathrm{gr} / \mathrm{cm}^{3}$ nilai koefisien serapan bunyinya paling besar. Syarat menjadi panel absorber adalah porositas yang tinggi, elastisitas atau kekakuan bahan yang tinggi, serta memiliki ketebalan bahan yang semakin tebal. Permukaan bahan yang berpori menyerap suara lebih baik dibandingkan dengan bahan yang tidak berpori atau berpori rapat. Hal ini karena bunyi yang masuk disebarkan melalui panas dalam (internal heat) yang dihasilkan oleh gesekan molekul antara molekul udara dengan struktur bahan (Karlinasari dkk, 2011).

Komposit SBP Polyester dengan semakin banyak seratnya menunjukkan bahwa ikatan interfacenya sangat kuat sehingga komposit SBP Polyester mempunyai kerapatan $\rho \geq 1$, termasuk dalam material berkerapatan tinggi dan mampu menyerap 84\% gelombang bunyinya. Komposit SBP Polyester dapat direkomendasikan sebagai bahan penyerap bunyi pada frekuensi rendah $(400 \mathrm{~Hz})$ dan pada frekuensi sedang $(100 \mathrm{~Hz})$. 


\section{Kesimpulan}

Komposit SBP Polyester mampu menyerap bunyi dengan baik pada frekuensi sedang $(1000 \mathrm{~Hz})$, dengan koefisien penyerapan bunyi sebesar $\alpha=0,84$ pada komposit SBP Polyester. Sedangkan pada frekuensi rendah komposit SBP Polyester mampu menyerap bunyi pada frekuensi rendah $(100 \mathrm{~Hz})$ dengan $\alpha=0,47$. hal ini menunjukkan bahwa komposit SBP mampu menyerap bunyi dengan baik untuk frekuensi rendah dan frekuensi sedang, sesuai dengan standar ISO 11654:1997 (E) dimana koefisien serapan bunyi bahan akustik minimal sebesar $\alpha=0,15$.

Pada hasil penelitian nampak adanya harapan untuk pengembangan komposit SBP Polyester sebagai material penyerap bunyi. Namun demikian, hal tersebut masih harus beberapa tahapan lagi, dibutuhkan penelitian lanjutan meliputi pengujian porositas komposit SBP terkait dengan aplikasinya sebagai penyerap bunyi

\section{Daftar Pustaka}

Doelle, L. 2006 BR. Akustik Lingkungan. Diindonesiakan oleh Prasetiyo. Jakarta: Erlangga

Karlinasari, dkk. 2011. Sifat Penyerapan dan Isolasi Suara Papan Wol Berkerapatan Sedang- Tinggi dari Beberapa Kayu Cepat Tumbuh. Jurnal Ilmu dan Teknologi Hasil Hutan 4(1): 8-13

Kartini, Ratni. dkk. 2002. Pembuatan dan Karakterisasi Komposit Polimer berpenguat Serat Alam. Jurnal Sains Material Indonesia, Vol.3, No.3 hal: 30-38. ISSN : 1411-1098

Mediastika. 2009. Material Akustik Pengendali Kualitas Bunyi pada Banguna. Yogyakarta: Andi Offset.

Mitchell, B. 2003. An Introduction to Materials Engineering and Science. New Jersey: John Wiley and Sons

Nasmi, H dkk. 2011. Analisa Kekuatan Tarik Komposit Termoplastic Diperkuat Serat Pohon Pisang Dengan Arah Serat Searah. Jurnal Teknik Rekayasa.Vol. 12, NO.1 Juni 2011. Universitas Mataram

Noni, N. 2013. Pengaruh Ketebalan Serat Pelepah Pisang Kepok (Musa Paradisiaca) terhadap Sifat Mekanik Material Komposit Poliester-Serat Alam. Jurnal Fisika Unand Vol. 2, No. 3 ISSN 2302-8491

Nurdiana \& Isranuri, 2011. Studi Karakterisasi Penyerapan Suara pada Komposit Polymer Dengan Serat RookWool. Jurnal Dinamis Volume II No. 8 Januari 2011. ISSN 02167492

Satwiko, P. 2009. Fisika Bangunan. Yogyakarta: Andi Offset 